\title{
Édipo e Perseu na iconografia clássica
}

\author{
ORDEP SERRA \\ Departamento de Antropologia \\ FFCH - Universidade Federal da Bahia
}

\begin{abstract}
RESUMO: Neste artigo, o autor faz uma comparação entre a iconografia de Édipo e a de Perseu, focalizando um aspecto da narrativa pictórica que permite a correlação entre os mitos desses heróis: um contraste visível na maneira como eles confrontam seus adversários (a esfinge, em um caso, $e$ no outro, a Górgona). No que toca a Édipo e sua inimiga, um dos mais constantes elementos da representação, na pintura cerâmica, é uma espécie de duelo visual entre os dois, cifra do repto enigmático. No que tange a Perseu, em sua luta com a Górgona, os artistas dão destaque ao modo como o herói evita a contemplação da adversária. O autor procura explorar o significado deste contraste que aproxima de modo inesperado duas séries míticas, e chama a atenção para a importância da mitopoiese iconográfica.
\end{abstract}

PALAVRAS-CHAVE; Édipo; Perseu; iconografia; mitos; pintura cerâmica; monstros.

A construção do mito, ou dos mitos trágicos de Édipo, deve muito ao legado da imaginária: o personagem Édipo surge também da representação figurada do herói. JeanMarc Moret mostrou que este aparece enquanto figura, enquanto ícone presente em obras pictóricas, num "cenário" já constituído antes... e dominado pela esfinge. Na pintura cerâmica, Édipo é fundamentalmente o grande antagonista da moça feroz. Mas a composição de cenas narrativas envolvendo esfinges e homens é anterior à aparição do filho de Laio na cena dominada pelo bicho fantástico que, mais tarde, lhe seria associado de forma constante, quase ineludível. Nesse contexto, antes de dar-lhe espaço, ela aparece desafiando e confrontando outros, suas vítimas. Édipo chega depois, e demora um pouco até que seu duelo com o monstro venha a ser representado à parte das "assembléias de tebanos". O esquema pictórico que estabelece a relação entre o monstro e "parceiros" humanos nem sequer se limita ao motivo "agônico": como diz Ingrid Krauskopf (1994, 11; cf. idem, 1987, 329), "es gibt auch Kompositionen, in denen sich Sphingen und Mensch ruhig gegenüberstehen...” A helenista infere daí uma hipótese muito razoável:

Möglicherweise sind aus diesem Schema heraus frühe Bilder von Oidipus und der Sphinx entwickelt worden, so wie aus der an dem angreifendem Sphingen die der von der böotischen Sphinx attackierten Thebanern. 
Seja como for, a clave (dominante) do confronto que opõe a esfinge a seu vencedor é ocular: quase sempre ele são mostrados vis à vis - e muitas vezes olhando-se nos olhos.

O esquema, que daí por diante vai prevalecer de forma absoluta, embora já se afirme no século $\mathrm{VI}^{1}$, fixa-se no século $\mathrm{V}$ a.C., consolidando-se nas figuras vermelhas. A taça do Vaticano H 569, do Pintor de Édipo (circa 470), mostra com vigor a confrontação dos olhares, com o herói sentado, de mão no queixo, mirando de forma direta a inimiga postada em sua coluna: Édipo ergue para ela as vistas, numa desassombrada reflexão. Infelizmente só restou um fragmento de outro testemunho precioso, num caco do colo de uma cratera de volutas hoje no Museu Britânico (E 812.3), posterior coisa de uma ou duas décadas à famosa taça que acabo de citar. Aí também o herói está sentado, mas no mesmo nível que a Esfinge, e muito perto dela: vê-se o bastão (inclinado) em que ele se apoia, a pequena distância entre seu joelho e o peito da fera; os rostos dos adversários estariam, sem dúvida, na mesma altura, encarando-se os dois num tête à tête próximo. $\mathrm{O}$ arranjo corresponde ao do citado vaso clazomênio, pioneiro nessa representação do encontro de Édipo com o monstro. Um lécito contemporâneo da taça "vaticana" do Pintor de Édipo (Princeton, 64-107) faz outra exposição do motivo: Édipo é representado como se estivesse a seguir caminho e fosse detido pela interpelação da esfinge, voltando o rosto para trás; sua atitude é tranquuila e ele encara a inquisidora posta sobre sua coluna. Neste caso, o confronto é menos incisivamente marcado em termos de oposição das imagens, mas a cabeça do monstro e a do herói se acham figuradas à mesma altura e seus olhares se cruzam diretamente.

Numa cratera de colunatas de meados do século V a.C., que hoje pertence ao Museu Paul Getty (Malibu 82 AE 143), o confronto dos olhares se dá também de modo próximo e direto, face a face. Édipo, de pé, volta-se para a fera sobre a coluna; apesar disso, o arranjo difere muito do empregado no lécito de Princeton há pouco citado: neste caso, o herói não “torna atrás", vira-se lateralmente para a inquisidora. Há duas testemunhas que compõem a cena, uma em cada extremo, cercando os protagonistas. (A outra face do vaso mostra três jovens que parecem conversar de forma perplexa e agitada: evidentemente, trata-se de tebanos fulminados pelo enigma).

O confronto solitário dos antagonistas que se encaram de forma direta, cabeças mais ou menos à mesma altura, é representado nas imagens de um pintor do grupo de Polignoto, sobre uma ânfora de asas retorcidas de circa 440 (Oxford, 1920), assim como num outro vaso do mesmo tipo, do Pintor de Munique, de 440/430 (Munique, 2321), e num stamnos seu contemporâneo, obra do Pintor de Menelau (Louvre, G, 417), ou numa ânfora de Polignoto, de 440 (Nápoles, H 3131).

O padrão mais recorrente é o que coloca a esfinge em posição de eminência. Numa bela ânfora do Louvre, datável de 440 (Louvre, G534), essa colocação sobranceira do monstro parece mais acusada por um artifício da representação: o traçado da coluna acompanha a curvatura da pança do vaso, que é bojudo, de maneira que essa coluna se "encurva", e a esfinge plantada sobre o pedestal ganha um movimento incisivo, como a inclinar-se para baixo, rumo ao ponto onde Édipo se detém, sustentando-lhe o olhar. Numa conhecida ânfora de 440 a. C, hoje em Oxford (Oxford, 526), a Esfinge interpela Édipo mirando-o de cima, a uma distância marcada na vertical, embora próxima no plano do horizonte; numa cratera em forma de sino, da mesma época (Cratera de Port-Sunlight, LL 5041), a besta, a pequena 
distância, e apenas um pouco mais elevada que o herói, parece projetar-se rumo a este, de maneira agressiva; Édipo, sentado, um pouco inclinado para trás, suporta-lhe a mirada. Duas testemunhas de cada lado flanqueiam os antagonistas.

Édipo está em posição mais elevada que a Esfinge nos fragmentos de duas ânforas do Pintor de Aquiles, de 440 a.C. (ânfora de Boston 06.2447; ânfora de Munique SL 474), assim como num lécito do mesmo artista, de 440/430 (Melbourne, National Gallery of Victoria; Moret, cat. 80, pl. 26; $\mathrm{ARV}^{2}$ pl. 993/90). Nas figuras negras, um lécito de 480/470 (lécito de Frankfurt Li 530), mostra um certo equilíbrio na elevação das figuras dos antagonistas; numa taça-ésquifo de 460 (Jerusalém, P 2352) ${ }^{2}$, eles se acham no mesmo nível, mas Édipo se destaca pela altura e sua silhueta é a que apresenta uma inclinação mais forte e incisiva no rumo da Esfinge.

Muitas variações são possíveis a partir do esquema básico do contacto visual que os reúne, mas este contacto é o núcleo decisivo da cena, mesmo quando o pintor retrata um dos antagonistas de olhos baixos.

Por vezes, é o herói que assim se mostra, como se meditasse a resposta exigida pela fera recém-encarada... Veja-se, por exemplo, a reprodução do lécito perdido da coleção Lusieri (Moret, 1984, cat. 88), de 470/460 a.C. Também sucede aparecer a moça bestial cabisbaixa, como se sucumbisse ao desespero da inesperada derrota face ao inimigo surpreendente (veja-se, por exemplo, uma pélike de 450 a. C., que Beazley atribuiu ao Pintor de Perseu, e mostra um arranjo pouco usual: a esfinge ao rés do chão, dominada pelo olhar de Édipo... Cf. $\mathrm{ARV}^{2} 582 / 2$; trata-se da pélike de Nápoles H 162 inv. 86297); ou mesmo os dois, baixando as vistas de modo simultâneo, como se o sentimento do destino terrível de ambos os acabrunhasse - e eles o tivessem percebido nos olhos um do outro (cf. pélike de Berlin F 2355). Até nessas cenas em que os dois (já) não se desfitam, ecoa a mirada que os confrontou.

No século IV a.C., em vasos de figuras vermelhas que apresentam esse "motivo tebano", prevalece ainda a representação do confronto próximo vis à vis Édipo x Esfinge, com os antagonistas a mirar-se diretamente, cabeças na mesma altura: isto se vê, por exemplo, numa enócoa do Pintor da Ilioupérsis, de 350 a. C. (Moret, cat. 107, pl. 66), assim como no ésquifo de Ancona 21.206 datável de 340/30, e numa pélike da mesma década, hoje em Leningrado (RB 3.38, fig. 75).

É bem conhecido o esquema do "duelo visual" em que os pintores cerâmicos transpuseram, com habilidade, o lance do enigma proposto pela esfinge a Édipo. Tem variações múltiplas, que as peças citadas documentam bem. Mas a "tradução visual" da proposição do enigma é um motivo que não se limita a cenas protagonizadas pelo herói, na pintura cerâmica. Numa taça hoje no Louvre (G 2660), de cerca de 480 a.C., em figuras vermelhas, obra de Mácron, vêem-se os tebanos representados por homens de diferentes faixas etárias. A esfinge, de pequenas proporções, de bote armado no topo de uma coluna, projeta-se para a esquerda. A rigor, ela está quase a precipitar-se, garras avançadas, sobre um jovem sentado, apoiado à mesma coluna e envolto num manto. $\mathrm{O}$ moço ameaçado volta para a fera a cabeça, com ar de assombro... Um outro jovem, atrás e à esquerda dessa vítima indefesa, principia a correr, com um braço erguido e uma expressão de espanto. Do outro lado da coluna, um homem adulto, sentado de costas para a cena tremenda, volta os olhos rumo a ela; adiante, um moço de pé, com ar de espanto, olha na mesma direção. Este conjunto se acha flanqueado pelas alças da taça; girando-a de modo a colocá-las 
nas direções opostas às que têm quando se vê o quadro já descrito, contempla-se um outro que o complementa, com quatro personagens a correr, em atitudes que revelam pânico e sugerem a troca de mensagens perplexas, carregadas de sobressalto ${ }^{3}$.

Mácron parece ter querido acentuar um elemento da narrativa pintada: a interpelação da Esfinge e o rumor que ela provoca, o pânico que suscita ao espalhar-se a notícia de seus ataques. Contudo ele mostra ainda outra coisa: o enleio mortal do jovem que a Esfinge assalta.

Num stamnos de Munique, [2405 (J 352); cf. Moret, 1985, cat.31 pl.18)], pintado em figuras vermelhas, de uma data entre 480 e 470 a. C., na cena visível em um dos lados do vaso, a Esfinge, sobre uma coluna, está flanqueada por dois jovens de pé, e mira o da direita, dando as costas ao outro. A cena que se divisa do lado oposto é quase a mesma - com a diferença de que a esfinge mira o moço da esquerda, voltando a cabeça para trás. As duas podem ser lidas em seqüência, na ordem em que as evoquei: na última, a esfinge volta-se, acompanhando o gesto do moço ao qual dá as costas. Este parece apontar no rumo oposto, feito se indicasse o parceiro: estaria a "passar adiante" a questão. O "pintor de Wurzburg” terá querido descrever a interpelação sucessiva de duas vitimas do monstro: focalizou o enunciado do enigma e a reação perplexa dos indagados. Ainda aqui, a principal informação é sobre o diálogo verbal; mas o jogo dos olhares, além de constituir o veículo da representação pictórica desse colóquio-desafio, é em si mesmo significativo.

Considere-se agora um ésquifo em figuras negras do Pintor de Teseu, obra datável de 490/80 a C. (Museu de Atenas, 18.720). De um lado, vê-se a Esfinge sobre uma coluna, asas na vertical, ancas mais elevadas que o peito, uma garra a projetar-se para baixo, olhos fitos num jovem todo encolhido em seu manto, sentado numa pedra; atrás dele, um cavaleiro nu assiste, à altura de cuja nuca, mais atrás, vê-se a figura imprecisa do que seria um pássaro - ou quiçá uma ave falo, segundo conjetura Moret (op. cit., p. 42 e pl. 25). Por trás da Esfinge, um bode mira com espanto. Do outro lado, vê-se quase a mesma cena, com algumas diferenças: as testemunhas por trás do jovem são um homem e uma mulher; e a atitude da Esfinge é ainda mais agressiva: ela está quase saltando sobre sua vítima, rumo a cuja cabeça projeta a sua, feito se quisesse penetrá-la com os olhos.

A aparência do rapaz é inteiramente fúnebre. Quem está acostumado a contemplar as obras de arte cemiterial dos gregos antigos, logo reconhecerá no infeliz uma "pose de morto", por assim dizer. O que ele tem de ainda vivo são os olhos arregalados... por onde o estupor da morte o penetra, segundo o artista dá a entender.

A Esfinge inocula a morte em suas vítimas - é o que mostram numerosas pinturas de vasos em que o monstro é mostrado interpelando os tebanos.

Ninguém negará que Édipo tem algo em comum com Perseu... (Ambos eliminam sem querer um ascendente: o pai, no caso do primeiro, o avô paterno, no do segundo). Mas num aspecto decisivo eles dois se situam em campos opostos.

Isto ocorre justamente no que toca à relação de cada qual com o monstro que derrotou.

O filho de Dânae não enfrenta a górgona, ou pelo menos não a defronta. Ele toma todos os cuidados para não mirá-la em face; aproxima-se de Medusa adormecida, quando ela teria os olhos cerrados (Cf. Apollod. Bibl. II, 4, 1 ss. Hyg. Fab. 63; Hes. Theog. 276 ss. 
Scut. 222 sq. schol. Ap. Rhod Arg. IV, 1091) e mesmo assim a degola sem a contemplar. Na iconografia, por sinal, Perseu tem sempre o rosto desviado; e o monstro inconfrontável é mostrado de frente para o espectador...

O certo é que esse herói não encara a inimiga nunca. Veja-se, por exemplo, a decoração em relevo de um escudo do século VI (circa 550), do museu de Olímpia B 975 (Schefold, 1978:82), com a representação de Perseu prestes a degolar a górgona com sua espada, ajudado por Atena. O herói segura com a mão esquerda uma das serpentes que emergem da cabeleira da adversária, e empunha com a destra a arma cuja lâmina já toca o pescoço da infeliz; do outro lado (à direita), a deusa agarra outra serpente da coma da medonha, que assim ajuda a imobilizar. Atena, de perfil, olha para a frente; a górgona é mostrada em posição frontal, encarando o espectador; mas Perseu, de perfil como sua auxiliadora, volta a cabeça para trás. Uma hídria ática do British Museum (E 181) mostra o protegido de Atena a fugir, mirando de relance o corpo que já decapitou, e cuja cabeça em parte se vê (o contemplador do vaso a enxerga) na kíbisis. Numa cratera ápula que hoje se acha em Boston (MFA 1970.237), Atena ergue na destra a cabeça da fúria degolada, e o herói mira-lhe $\boldsymbol{o}$ reflexo no escudo. Cf. FrontisiDucroux, 1995, f. 18 e f. 21.

Pois bem: a esfinge, pelo que mostra uma série de pinturas onde ela é representada a desafiar suas vítimas, de certo modo as "petrificava", feito Medusa: nas imagens, vem de seus olhos o horror que bloqueia, enigmático...

Mas seu vencedor encarou-a, e resistiu a seu fascínio.

Édipo jamais se vê representado virando a face em rumo oposto ao da esfinge. Em algumas pinturas, onde a enfrentam outros adversários, é ela que realiza a apostrophé. Parece que assim o monstro preludia o lance fatal.

Em suma, a mirada da esfinge é uma interpelação que exige réplica. O enigma indecifrado se traduz, nas cenas mostradas por diversos vasos antigos, pelo bloqueio do homem de olhos mudos a quem o monstro mira de morte (ver, por exemplo, a taça de Siracusa 25418, em figuras negras, do Pintor C, datável de circa 570-560, e a taça de Amsterdã 6242, figuras negras, circa 550). O enigma decifrado se vê também numa expressão de olhos serenos, que reagem aos da inquisidora. Até mesmo numa pintura onde o confronto de Édipo com a sua adversária se apresenta feito um combate ${ }^{4}$, conforme sucede num lécito do Pintor de Aquiles (o lécito de Nicósia C 6294; cf. Moret cat. 104, pl. 62/2-3), o olhar que trocam os antagonistas é decisivo. Recordo que nas figuras deste lécito o herói surpreende a traiçoeira, voltando-se, numa espécie de finta, para lhe opor sua lança erguida, quando ela já salta no ataque: o olhar que Édipo relanceia antencipa o golpe da lança, e o monstro colhe esse lampejo nas pupilas desmesuradas, que lhe dão ao rosto uma expressão de paralisia, em agudo contraste com a forma impulsiva do corpo. Édipo vira-se, pois, para encarar de surpresa a inimiga, que fere primeiro com um olhar agudo, precursor da lança. Ele finta, não foge...

Pelo contrário, a fuga é um elemento essencial da façanha de Perseu. Recorde-se a cena representada numa taça do Pintor C (Londres, B 380), datável aproximadamente de 560, onde não apenas Perseu mas também seus divinos protetores, Atena e Hermes, fogem às carreiras da Górgona.

Este é apenas mais um traço de uma oposição que merece destaque, pois percorre diferentes planos. Na iconografia, a inimiga de Édipo é um monstro com aspecto de mulher 
bonita; a Górgona que Perseu ataca tem uma feiura espantosa. O filho de Dânae triunfa com ajuda divina, assistido de perto por dois olímpicos que lhe fornecem (eles e as ninfas) os meios de triunfar; Édipo enfrenta sua adversária sozinho, sem socorro de numes prómakhoi. A esfinge, sempre vigilante, tem a iniciativa, o herói só lhe replica; são poucas as representações desse confronto em que o mesmo se descreve como um embate violento, mas até quando isto ocorre, em exemplos significativos, a fera é quem ataca, traiçoeira... Já no caso do vencedor de Medusa, a violência é a regra, a iniciativa pertence ao herói, e ele ataca sorrateiramente: embosca a adormecida. Enfim, Perseu é o herói que desvia o rosto ao acometer a inimiga monstruosa; Édipo é o herói de um confronto face à face. No universo das imagens, esta oposição tem um valor axial. Sem considerá-la, não se pode empreender o estudo de uma "iconografia do olhar" no mundo antigo.

Essa gramática ocular é certamente um achado antigo da imaginária, e aprofunda o mito. As esfinges simétricas que se contemplam e se replicam ao modo de figuras no espelho instituem a clave dos olhares para a cifra do enigma.

A forma-esfinge insinua-se na arte grega de modos distintos: já bem cedo, na pintura cerâmica (como também na glíptica) encontra-se em grupo, "em procissão" - e também feito imagem singular, circunscrita, ou não, a um campo limitado por frisos, barras etc. Mais comumente, ela aí compõe dupla, com a oposição simétrica bilateral dos seus ícones contrapostos (por exemplo, ao pé de uma "árvore da vida", esquematicamente representada por um floreado geométrico $)^{5}$. As esfinges em par confrontam-se ainda flanqueando um deus, um ser demoníaco, ou uma besta; ou acham-se em oposição direta, sem outro ícone a separá-las, com as imagens replicadas "encarando-se" de maneira incisiva, olhos nos olhos. Deve relacionar-se com este um outro uso da imagem legendária, comum na pintura cerâmica do século VII e VI, onde freqüentemente ela figura "als Todesdämon (ker) in der Begleitung von Kriegern" (Demisch, 1977:76). Segundo creio, esses modelos influenciaram de um modo decisivo a representação da esfinge interpeladora/ arrebatadora dos tebanos, que corresponde à mítica de Édipo, mas a integra de um modo especial.

Na história do emprego pictórico da figura da esfinge no mundo heleno merece destaque sua progressiva consagração ao empenho significativo do olhar, à significação do olhar - quase sempre em situação "agônica", de confronto. O combate enigmático do monstro com Édipo (ou com vítimas sem saída, no contexto da saga tebana) é o mais recorrente nessas narrativas icônicas. Mas não é caso único. Em outro contexto, esfinges dramatizam atitudes em que o olhar instaura a diferença, refletido e desviado.

Uma pequena taça ática do Museu de Cluny (Inv. D.08.3.4; cf. CVA 29, pl. 19/1, 2, 3, e p. 25), pintada em figuras negras, datável dos fins do século VI (circa 520, quiçá), de um dos lados, apresenta duas esfinges em pose antitética, traçadas com um mesmo padrão de desenho, mas com atitudes um tanto diferenciadas, numa agradável quebra da rigidez do esquema de oposição bilateral plenamente "especular". A esfinge da direita, menos comprida, de colo e rosto menor que a da esquerda, parece ter o busto mais empinado... Pois bem: no outro lado da taça, uma esfinge muito semelhante a essas duas, desenhada de acordo com o mesmo padrão, acha-se representada numa atitude bem diversa, pois estaca com apenas um 
dos membros dianteiros a prumo, a pata correspondente apoiada no "chão": tem o outro levantado e fletido de modo que lembra um gesto de chamamento. Esta esfinge volve o rosto para trás, numa torção muito "completa" e rigorosa... É notável essa apostrophé. À sua frente, vê-se a correr um jovem nu, que também volta para trás a cabeça, como que a fim de olhar o monstro, do qual visivelmente foge. Reconhece-se logo o que parece extravagante na composição da cena descrita: a princípio, hesita-se em chamar de "perseguidora" a esfinge: ela se detém numa posição perfeitamente insólita para um predador ativo, e volta o rosto no sentido oposto ao da possível vítima, como se não tomasse conhecimento dela, ou mesmo evitasse encará-la. Mas o estudioso da iconografia grega antiga não tem como ceder a esta interpretação "otimista": a face do monstro virada para trás evoca um toque tanático ${ }^{6}$.

Este pintor não imaginou a esfinge como um protagonista perfeitamente individualizado de uma ação mítica nominada. Basta o giro da taça para comprová-lo: ocorre aqui coisa bem diferente do que sucede no caso da famosa ânfora de Stutgartt [(65/15, circa 530 a. C.), na qual, em um dos lados, o herói confronta a besta, e, no outro - num campo bem destacado -, acham-se duas esfinges a mirar-se... Na taça de Cluny, quando o contemplador a gira, não se percebe mudança de cenário, de campo de mensagem. A cena é uma só.

Estamos longe da saga tebana... Vamos um pouco mais longe.

Observe-se a presença quase plácida de uma esfinge que se vê a assistir (mas de olhos nos olhos do Velho do Mar, enquanto o herói mira noutro rumo) a luta de Héracles e Nereu, num fragmento de hídria do Pintor KX, hoje no Museu de Samos (K 2294) ${ }^{7}$. A esfinge evoca o demoníaco poder de metamorfose do Velho divino, suas viragens monstruosas, sua natureza polimorfa, o fascínio do ambíguo profeta, capaz de assumir aparência teriomorfa, de misturar, na sua, diferentes naturezas.

O ícone esfinge tem uma valência múltipla que os artistas gregos exploram de maneira sutil. Quando o empregam na composição de uma narrativa pictórica, nem sempre deixam de lado seu caráter emblemático, a riqueza de conotação derivada de seus papéis adjetivos.

As esfinges precedem "a Esfinge", e esta não as abole: até "convive" com elas no mesmo horizonte mítico-pictórico.

Com isso, volto a Édipo...

Considere-se agora a ânfora pseudo-calcídica de Stutgart 65/15: aí se acha uma das mais notáveis figurações do duelo visual entre o herói e a inimiga. No anverso do mesmo vaso, em campo destacado, encontra-se uma outra cena surpreendente: duas esfinges se confrontam, idênticas, em arranjo simétrico bilateral, a mirar-se nos olhos uma da outra.

As duas faces da representação se comprometem. O mito de Édipo é relacionado com o horizonte de uma fabulação indefinida, que lhe acrescenta uma nova dimensão de significado. Um horizonte mítico penetra em outro. O conjunto das duas esfinges é, em princípio, um arranjo "não narrativo", emblemático: muitas centenas de representações podem ser encontradas em que pares de esfinge compõem uma espécie de décor. Mas na ânfora de Stutgart, temos uma apresentação simultânea de dois usos da forma esfinge.

(Está claro que esta simultaneidade deve ser qualificada: é preciso passar de uma representação a outra girando o vaso, ou girando em torno do vaso. Mas quando se faz esta 
passagem, a cena que ficou escondida aos olhos do espectador logo lhe assalta a memória e se projeta sobre a visão da outra. Acabo de ver a representação do duelo visual entre Édipo e a Esfinge; contornei a ânfora e admiro a representação que lhe é oposta. Impossível não pensar na homologia sutil entre o confronto agora visível e o outro que acabei de ver. O movimento que fiz foi evidentemente previsto pelo pintor, que contou com ele, e o tornou em elemento sutil de sua exposição).

É possível que o confronto "visual" Édipo x Esfinge tenha nascido, enquanto mito icônico, da oposição "especular” de figuras de esfinges simétricas, na escultura (na composição arquitetônica) e depois na pintura.

Isto me leva a outro ponto: a aproximação assimilativa que se dá entre Édipo e sua inimiga. Perseu se opõe à Górgona de todo modo; nada o aproxima dela diretamente (até mesmo no combate, ele pratica uma aproximação "indireta"; herói e monstro nada comungam, neste caso (e a simples comunhão do olhar é o que o Perseu desde logo evita). Mas Édipo acaba por revelar-se essencialmente próximo da esfinge: semi-humano e semi-bestial, enigmático: ele é, para si mesmo, um enigma monstruoso. Ele parece espelhar a esfinge que confrontou num estranho agón. (Em Rei Édipo, o "momento da esfinge" é o agón dos dois cegos). Outro contraste entre Perseu e Édipo se acha no fato de que o primeiro "instrumentaliza" sua vítima, torna-a uma arma sua, que mantém destacada de si - à mão, mas longe de suas vistas... Édipo nenhuma defesa tira do monstro vencido, segundo o comum paradigma heróico. Não a "instrumentaliza", pois. Mas parece que a incorpora.

Ao cabo, da façanha de Perseu resulta o gorgonêion, deslocada cabeça, um invisage como diz a Prfa. Frontisi-Ducrout; da façanha de Édipo, resulta sua “anti-máscara”. Reportome aqui a Claude Calame, ao que ele diz sobra a cegueira auto-provada por Édipo, elemento da composição dramática de OT. Ver Calame, 1996, p. 28: "In blinding himself, Oedipus calls into question not only his own identity as actor inthe drama, but also that of the wearer of his mask..." E ibidem, p. 29: "The revelation of the truth guaranteed by the god means the end of the dramatic illusion. If the self-blinding takes Oedipus to the limits of human knowledge, the same gesture takes him to the limits of tragic staging".

Dos contrastes, emerge um encontro - no campo do que chamarei (sem dúvida, impropriamente) de anti-prosopopéia.

\section{Notas}

1 - Veja-se, por exemplo, a ânfora clazomênia do British Museum B 122, peça fragmentária, datável de circa 540 e a ânfora pseudo-calcídica de Stutgart, 65/15 circa 530.

2 - Moret, 1984, cat. 97, pl. 57-1; idem, ibidem, cat. 99, pl. 57.

3 - Mais à esquerda, um jovem e um adulto tomam a mesma direção, o segundo de cabeça voltada para trás; adiante deste, do centro para a direita, um outro varão, barbudo e careca, visivelmente mais velho, corre no mesmo rumo; e um quarto personagem, um homem robusto, vem vindo a seu encontro.

4 - O testemunho literário mais antigo que se pode invocar com alguma segurança em favor da existência da variante do combate físico entre Édipo e a esfinge é um frag. de Corina (o frag. 
672 Page). O documento inconográfico que parecia melhor situado para sugerir a maior antiguidade dessa versão (um lécito do Museu de Boston, de matrícula 97. 374) acabou por revelar-se obra de falsário; e a descoberta posterior (feita em 1972) da ânfora pseudo-calcídica de Stutgart (65/15), aduziu mais um testemunho de que a variante suposta tardia (ou seja, a da disputa enigmática, sem armas), já era presente na segunda metade do século VI. Em suma, no que toca à imaginária, os vasos que documentam a versão do combate físico entre Édipo e o monstro são todos do século V. Não há razão para atribuir ao conteúdo desses testemunhos maior antiguidade que ao de outros, dedicados à representação da cena do enigma. Estes são seus coetâneos, ou mais antigos. No que toca à proeza de Édipo, ao contrário do que sustentava Delcourt [ 1981 (1944): 106], a imaginária concentrou-se no motivo da interpelação, do desafio enigmático.

5 - Isso ocorre em relevos, gemas, entalhes, em trabalhos de metal e na pintura cerâmica.

6 - Veja-se, a propósito, um lécito em figuras vermelhas, atribuído ao ceramista e pintor conhecido como Pintor de Thánatos, obradatável de circa 460 a.C., onde Thánatos é representado com o corpo voltado para o espectador, mas a cabeça virada para o lado (lécito do Museum of Fine Arts, Boston 96. 721; cf ARV2 1299 no. 24.

7 - Cf. Beazley, 1958:21 e pl. 7/1 ( $A B V$ ). Esse frg. de hídria se acha. Cf. também M. Pipili, LIMC, Vol VI, 1 p. 826 (19), s. v. "Nereus".

\section{Referências bibliográficas}

BEAZLEY, J. D. Attic black figure vase painters. Oxford: Clarendon Press, 1956.

CALAME, C. "Vision, blindness and mask: the radicalization of the emotions in Sophocles' Oedipus Rex". In M. S. Silk (ed.): Tragedy and the tragic. Oxford: Clarendon Press, 1996. p. 18-37.

DEMISCH, H. Die Sphynx. Geschichte ihrer Darstellung von der Anfängenbis zu Gegenwart. Stuttgart: Urachhaus, 1977.

DESSENE, A. Le sphynx. Étude iconographique. Bibliothèque des Écoles Françaises d'Athènes et de Rome, CLXXXVI. Paris: Boccard, 1957.

FRONTISI-DUCROUT, F. Du masque au visage. Paris: Flammarion, 1995.

HERBIG, R. Sphynx. RE III A, 2, p. 703-1749, 1929.

KRAUSKOPF, I. Oedipus. LIMC, VII, p. 1-15, 1994.

MORET, J.-M. Oedipe, la sphynx et les thébains. Essai de mythologie iconographique. Institut Suisse de Rome, 1984.

PIPILI, M. Nereus. LIMC, Vol VI, 1 p. 826.

SIMON, E. Das Satyrspiel Sphynx des Aischylos. Heidelberg: Carl Winters. Universitätsverlag, 1981.

TRINDADE SERRA, O. J. O reinado de Édipo. Tese de Doutorado. São Paulo: Programa de Pós-Graduação em Antropologia Social / FFLCH- USP, 1996.

\section{Obras de referência}

Corpus Vasorum Antiquorum. [CVA]. Paris et al.: 1923-. 
LEXICON ICONOGRAPHICUM MYTHOLOGIAE CLASSICAE. [LIMC]. Zürich/ München: Artemis Verlag, 1981.

PAULY, A. F. von, WISSOWA, G. \& KROLL, W. (eds.): Paulys Realencyklopädie der Altertumswissenschaft. Neue Bearbeitung. 24 vols. 2 d ser. (R-Z) 19 vols. Stuttgart: J. B. Metzler, 1894-1972. Supplement. 15 vols. [PAULY/WISSOWA]. Stuttgart: J. B. Metzler, 1903-78.

TRINDADE SERRA, O. J. Oedipus and Perseus in the classical iconography. Classica, São Paulo, 13/14, p. 71-80, 2000/2001.

ABSTRACT: In this article, the author compares the classical iconographies of Oedipus and Perseus, focusing a particular aspect of the pictorial narratives which suggests a logical connection of the corresponding myths, through the remarkable contrast in the way each of these heroes does confront the demonic adversary (the Sphinx, in the case of Oedipus, the Gorgon, in Perseus' case). Ceramic painters used to represent a kind of "ocular duel" between Oedipus and the Sphinx; in the representation of Perseus fighting the Gorgon, they used to show how the hero turned his face, avoiding to look at the monster. The author endeavours to understand the meaning of this contrast, and calls attention upon the importance of iconographic mythopoiesis.

KEYWORDS: Oedipus; Perseus; monsters; iconography; ceramic picture; myth. 